\title{
Molten Salt-Fueled Nuclear Reactor Model for Licensing and Safeguards Investigations ${ }^{1}$
}

\author{
M. Scott Greenwood ${ }^{1}$ \\ ${ }^{1}$ Oak Ridge National Laboratory, Oak Ridge, TN, USA greenwoodms @orn l . gov
}

\begin{abstract}
Fluid-fueled nuclear reactors, particularly molten salt reactors (MSRs), have recently gained significant interest. As with all reactors, modeling and simulation are key factors for advanced reactor design and licensing and will be required for the deployment of MSRs. However, there are significant gaps between simulation capabilities and system behavior for MSRs. This paper presents the system model of an MSR that is based on the Molten Salt Demonstration Reactor. The model includes important physics specific to MSRs, such as fission product and tritium transport and reactivity feedback.
\end{abstract}

Keywords: molten salt reactors, salt-fueled, nuclear

\section{Introduction}

The past few years have seen a significant increase in the interest of advanced fluid-fueled reactor systems, specifically molten salt reactors (MSRs). A fluid-fueled reactor is any reactor in which the fissile material is carried by the primary coolant throughout the primary flow circuit. Reactors such as MSRs could represent a revolutionary shift in the way nuclear power is implemented, and as a broad class of reactors, they have the potential to directly fulfill many US energy policy objectives.

Modeling and simulation are key for advanced reactor design and licensing. There are several modeling and simulation capabilities that can be used to investigate various aspects of nuclear reactors, including the Consortium for Advanced Simulation of Light Water Reactors (CASL) and the Nuclear Energy Advanced Modeling and Simulation Program (NEAMS). However, these have not been approved as licensing tools. Many of the capabilities from these and other programs are being adapted, or new ones are being created (Touran et al., 2017), to address the needs of advanced nuclear reactors and to ultimately generate tools that can be used for design and licensing of advanced reactors. Even so, significant technological gaps are preventing rapid development of these tools, such as lack of data or difficulties in adapting legacy code intended for alternative applications such as LWR technologies.

Development of a low-fidelity, system-level model was identified as a straightforward path to identifying needs and gaps in data and simulation capabilities. For example, a system level model would allow for sensitivity analysis of dominating parameters that require additional research (e.g., heat and mass transfer coefficients) and for the exploration of safeguards and nuclear material accountancy that is an active area of research for MSRs. The identification of the various needs and gaps will inform required modifications to existing capabilities, help direct experimental data generation, and assist in requirement generation for modern high-fidelity code generation. This paper describes a system-level model of a thermal fluoride salt-fueled MSR that was created using the Modelicabased TRANSFORM tool developed by the Oak Ridge National Laboratory (ORNL) (Greenwood, 2017a). Additional details can be found in the following reference (Greenwood et al., 2018).

\subsection{TRANSFORM}

The TRANsient Simulation Framework of Reconfigurable Models (TRANSFORM) is a Modelicabased library developed at ORNL (Greenwood, 2017b; R. Hale et al., 2015). The tool's primary purpose is to provide a common simulation environment and baseline modeling resources to facilitate rapid development of dynamic advanced reactor models. Critical elements of this effort include (1) definition of standardized, common interfaces between models and components, (2) development of a library of baseline component modules to be assembled into full plant models using available geometry, design, and thermal-hydraulic data, (3) definition of modeling conventions for model and component development, and (4) establishment of user interfaces and support tools to facilitate simulation development and analysis (R. Hale et al., 2015; R. E.

\footnotetext{
${ }^{1}$ Notice: This manuscript has been authored by UT-Battelle, LLC, under contract DE-AC05-00OR22725 with the US Department of Energy (DOE). The US government retains and the publisher, by accepting the article for publication, acknowledges that the US government retains a nonexclusive, paid-up, irrevocable, worldwide license to publish or reproduce the published form of this manuscript, or allow others to do so, for US government purposes. DOE will provide public access to these results of federally sponsored research in accordance with the DOE Public Access Plan (http://energy.gov/downloads/doe-public-access-plan).
} 
Hale, Cetiner, et al., 2015; R. E. Hale, Fugate, et al., 2015). The TRANSFORM library has been successfully used for a variety of projects, including investigations into the performance of nuclear hybrid energy systems (Greenwood, 2017c; Greenwood, Cetiner, et al., 2017; Greenwood, Fugate, et al., 2017; Rabiti et al., 2017) and tritium transport (Rader et al., 2018).

\subsection{Trace Substances}

The Modelica language allows for a class called a connector, which allows a set of variables to always be defined between the connection of two models (e.g., in a fluid system: pressure, mass flow rate, specific enthalpy of the fluid, mass fraction of each species in the fluid, and trace substance mass weighted fraction). This fluid connector is implemented in the Modelica Standard Library and is adopted by TRANSFORM throughout its thermal-hydraulic library. A key feature of this variation of the fluid connector is the inclusion of a variable that accounts for trace substances. This work employs the trace substance variable to track the behavior of fission products, including delayed neutron precursors, principal contributors of reactivity feedback (e.g., xenon) and decay heat, and tritium.

A trace substance is assumed to be present in such small quantities that it has an insignificant impact on the mass of the system. Trace substances are tracked as unspecified mass-weighted fractions of the primary flow, so they flow as a homogenous part of the primary fluid, but they do not participate in the normal mass balance of the primary fluid. The absolute units of the traced substances are user definable based on the application. For example, if the primary fluid flows at 1 $\mathrm{kg} / \mathrm{s}$ and a trace substance's (C) mass-weighted fraction is 100 atoms of $\mathrm{C} / \mathrm{kg}$ fluid, then the primary fluid mass balance assumes that there is $1 \mathrm{~kg} / \mathrm{s}$ of primary fluid, and the trace substance mass has its own mass balance tracking the 100 atoms/s flowing through the system. This method allows for mapping of small quantities of substances in traditional thermal-hydraulic processes as a first-order approximation, obviating the need to create complex media proprieties, pressure loss functions, etc. The behavior of the primary fluid is driven by its own mass, energy, and momentum balances.

\section{Model Criteria}

MSR development requires integrated performance models to understand the interaction and feedbacks between systems. As this model was intended to inform the development of salt-fueled reactors, necessary requirements of the model were identified from licensing and safeguards considerations. In broad terms, licensing and safeguards may be defined as follows:

- Licensing: The process by which the US Nuclear Regulatory Commission (NRC) ensures the protection of public health and safety, the common defense and security, and the environment (NRC 2010). Of primary importance are the types of radioactive sources and the pathways of exposure of those sources to site personnel and the public.

- Safeguards: "the timely detection of diversion of significant quantities of nuclear material from peaceful nuclear activities to the manufacture of nuclear weapons or of other nuclear explosive devices or for purposes unknown, and deterrence of such diversion by the risk of early detection" (Paragraph 28, INFCIRC/153) (IAEA, 1972).

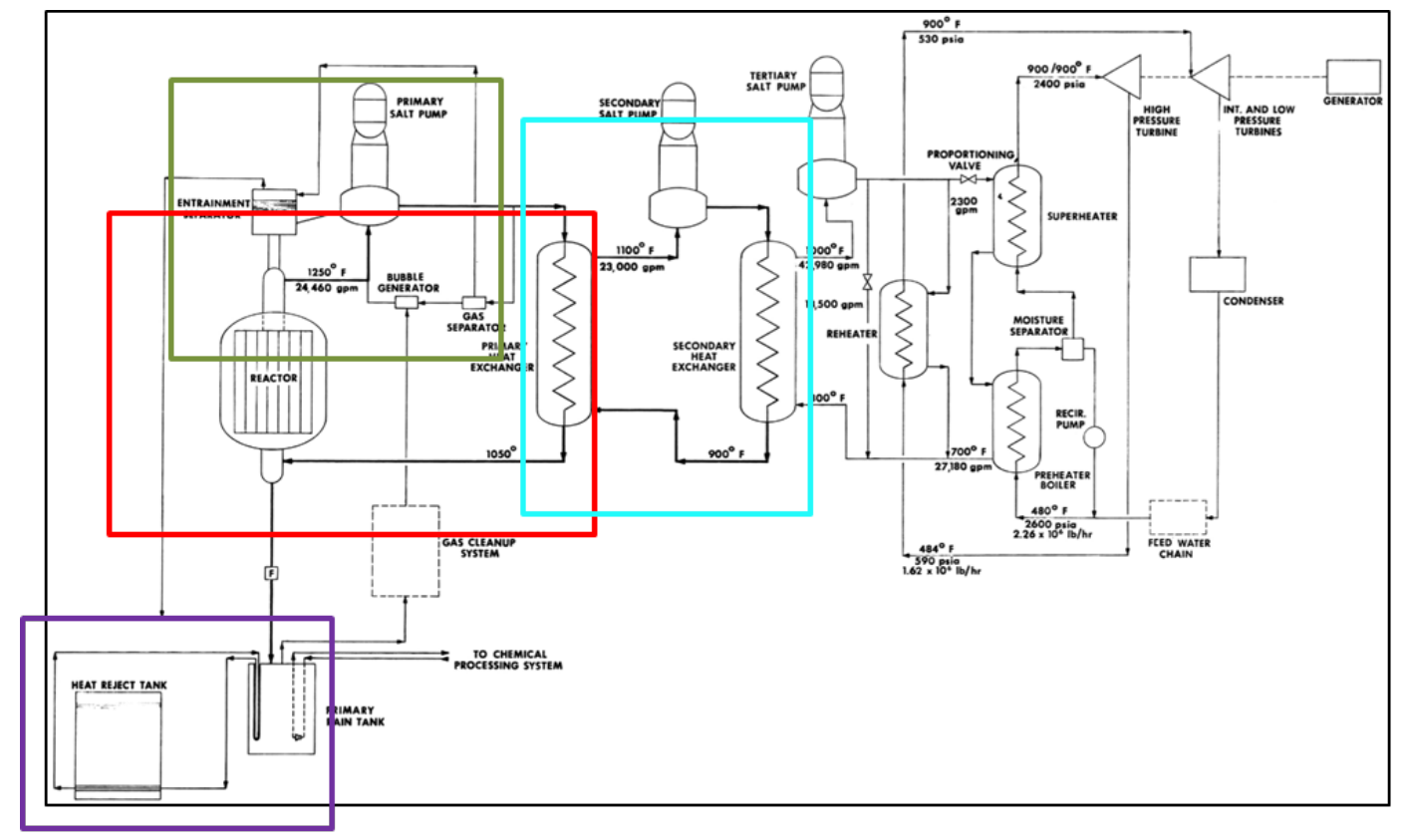

Figure 1. Simplified flowsheet of the salt-fueled thermal MSDR. Boxes represent corresponding systems between the MSDR flowsheet and the system model. 
In addition to licensing and safeguards, available data, historical experience, and current proposed MSR designs were also evaluated to guide the design criteria of the system model. Historical operational experience is limited to two small salt-fueled, thermal spectrum demonstration reactors, both of which were operated at ORNL (Rosenthal 2009). The Aircraft Reactor Experiment (ARE) was operated in 1954, and the Molten Salt Reactor Experiment (MSRE) was operated from 1965-1969. Numerous design documents, including balance-of-plant and auxiliary systems documents, were generated under the Molten Salt Breeder Reactor (MSBR) Program in the 1960s and 1970s. Modern MSR designs will need to understand the source term behavior in their systems for licensing and safeguards considerations, as well as performance of auxiliary systems such as off-gas and decay heat removal systems. The criteria required of the dynamic models are enumerated below.

1. Inclusion of delayed neutron precursor models that account for delayed neutron precursor production, transport, and decay throughout the primary fueled reactor loop (i.e., reactor core to primary heat exchanger and back) and auxiliary systems

2. Radionuclide inventory accounting, including source term production and holdup and release mechanism models

3. Thermal-hydraulic analyses of sufficient fidelity to capture flow and power dynamics in salt-fueled concepts

4. Time-, temperature-, flux-, and flow-dependent materials and salt interaction data, and models to predict corrosion, erosion, and irradiation effects
5. Modeled concepts that rely on existing data where possible to minimize development time while remaining relatively generic and applicable to modern MSR designs

\section{Model Development}

\subsection{Reference Design}

In accordance with the identified model criteria, the Molten Salt Demonstration Reactor (MSDR) (Bettis et al., 1972) provides the base design concept for the fluoride salt-fueled reactor dynamic model (Figure 1), with the exception that a $\mathrm{U} / \mathrm{Pu}$ fuel salt is used rather than the Th-fueled salt of the original concept. This concept has a nominal thermal output of $750 \mathrm{MWt}$. The purpose of the MSDR was to demonstrate the moltensalt reactor concept on a semi-commercial scale while minimizing development of basic technology beyond that already demonstrated by the MSRE.

An advantage of basing the reactor concept on an existing design is attributable to the detailed design document developed by researchers who were intimately familiar with the MSRE technology. The MSDR also leverages the work of the MSBR (Robertson, 1971) for information on off-gas, chemistry, materials, neutron physics, fuel reprocessing, etc., an effort which was also carefully documented. This model provides information that directly applies to the development of commercial reactors, minimizing development requirements and complication of systems. These elements help meet the near-term deployment targets of modern vendors.

\section{Off-Gas System \& Drain Tank}

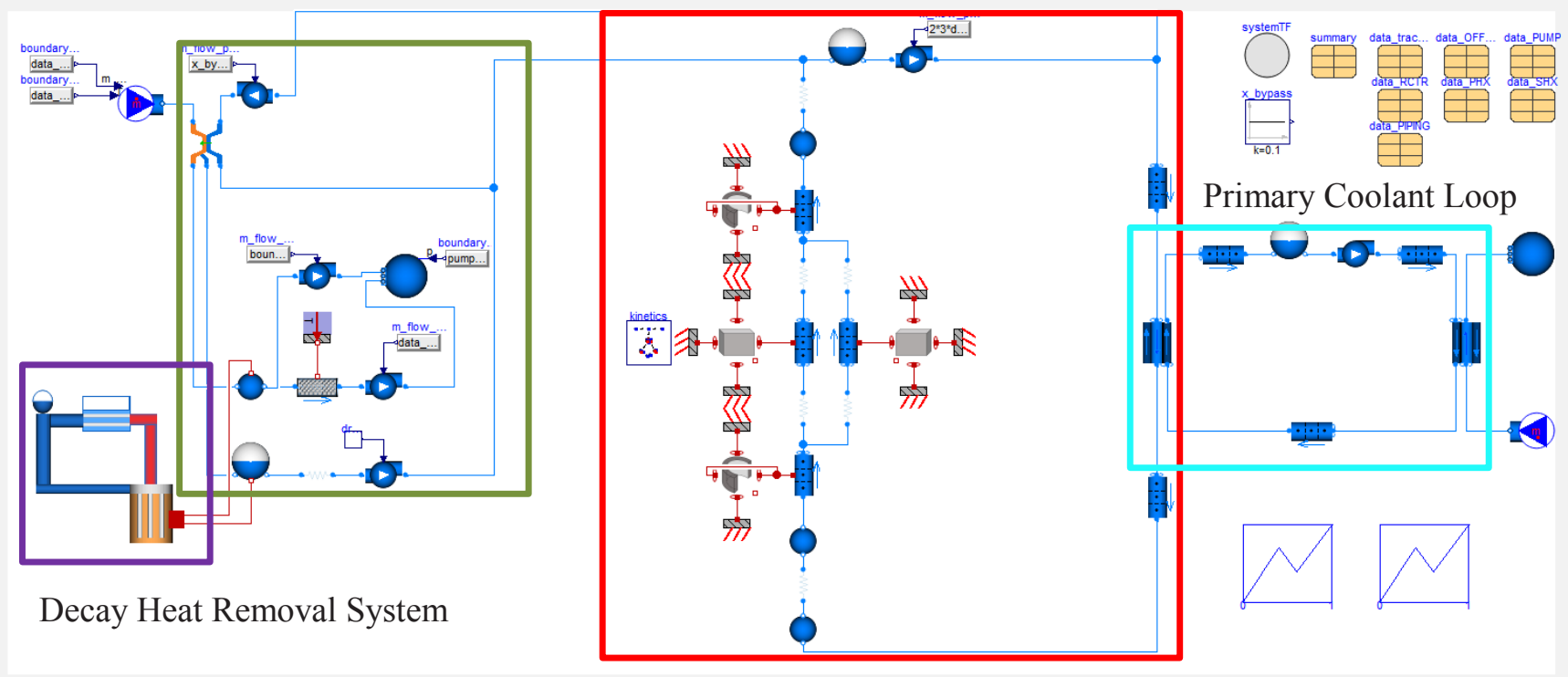

Figure 2. System model of a fluoride salt-fueled thermal reactor based on the MSDR. Boxes represent corresponding systems between the MSDR flowsheet and the system model. 


\subsection{System Model}

The system model (Figure 2) was developed based on the available MSDR literature and the identified criteria. Specific subsystems and other important phenomena are discussed in more detail below. Other critical systems that impact the reactor behavior such as the balance of plant (BOP) will be modeled in the future.

\subsubsection{Primary Fuel and Coolant Loop}

The primary fuel loop (PFL) is defined as the primary circuit of fuel salt, including the reactor, the primary fuel pump, piping to and from the primary heat exchanger, and the primary heat exchanger (fuel side).

The principal component of the PFL is the reactor (Figure 3). The reactor consists of an inlet and outlet plenum, two axial reflectors, a radial reflector, and the core. Since the surface area and volume of graphite and fuel salt are important not only for heat transfer considerations but also for interaction with trace substances, a concerted effort was made to preserve reactor geometries in the model.

The identical inlet and outlet plenums are ideally mixed volumes. The identical inlet and outlet graphite reflectors are made from radial rings of graphite, with each ring consisting of several smaller sections of graphite. The graphite is modeled as a $2 \mathrm{D}$ radial ( $\mathrm{r}-\mathrm{z}$ ) conduction model with a specified number of parallel graphite blocks. Heat and mass transfer are modeled on the inner and outer radial surfaces and neglected on the top, bottom, and edge. The fluid subchannel is represented by a 1D discretized homogeneous fluid, with geometry specified by the total cross section area and the wetted perimeter of the reflector.

The radial reflector consist of stacked rectangular slabs and is therefore modeled with a 2D slab (x-z) conduction model. The slab is assumed to have an adiabatic centerline which permits modeling only half of the slab. The entire slab can be modeled by increasing the number of parallel characteristic solids by a factor of two. Heat and mass transfer are neglected on the top, bottom, and small edge of the block.

The core region graphite (Figure 4) is also modeled with a 2D slab (x-z) conduction model with appropriate dimensions. The fluid channel was determined by the cross-sectional flow area and the wetted perimeter, in association with their respective graphite.

The pipes to and from the primary fuel heat exchanger dimensions are approximated based on rough estimations from drawings, as their dimensions were not specified in available documentation. Likewise, the pump and pump bowl were never fully defined, so the dimensions of the pump bowl were assumed to be

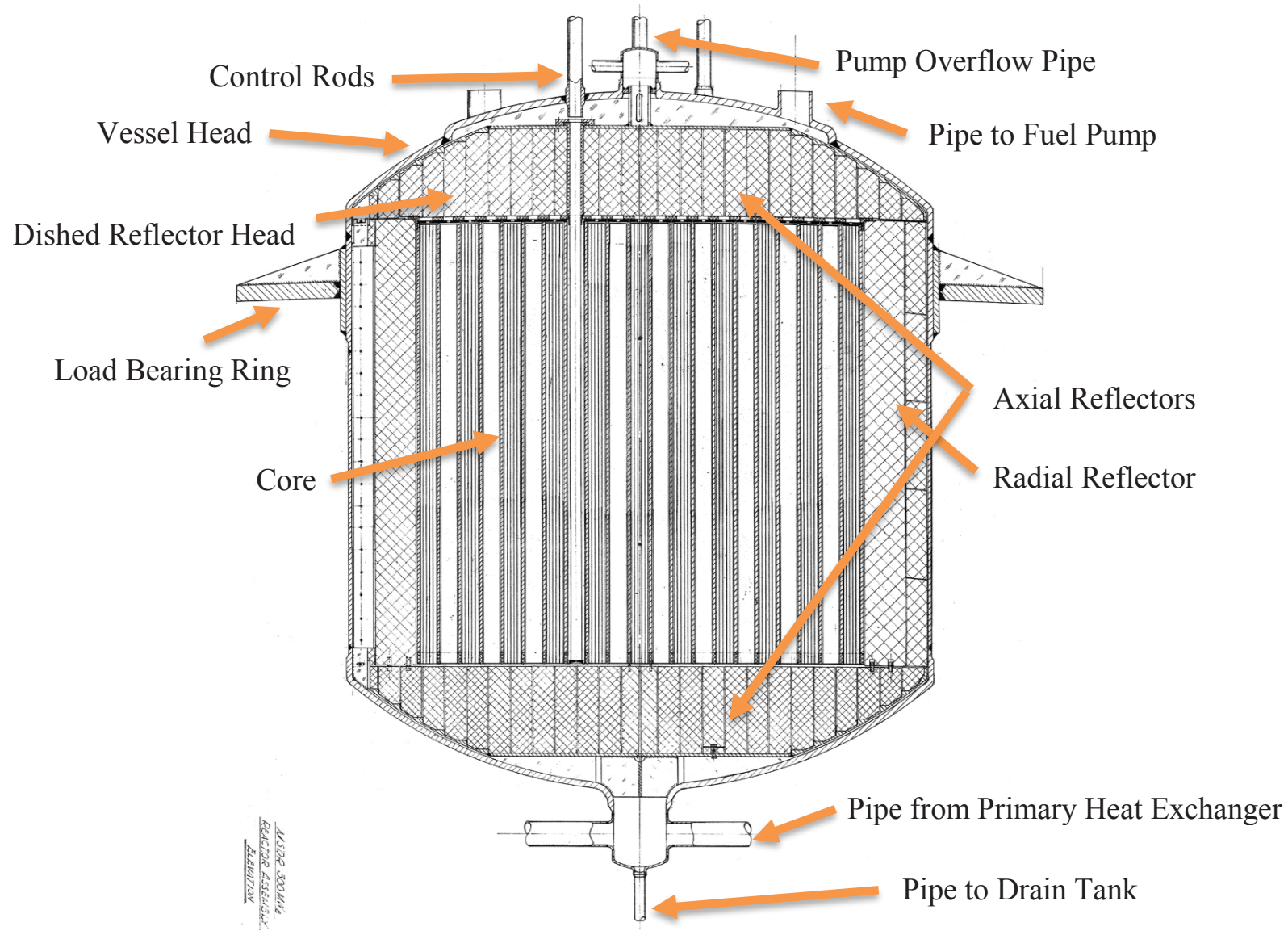

Figure 3. MSDR reactor vessel geometry (Bettis, Alexander, and Watts 1972, Fig. 2, ORNL DWG 72-2829). 
similar to those in the MSBR. The off-gas system interfaces with the primary loop at the pump bowl inlet and the pump outlet by cycling a fraction of the overall flow through a separator to strip fission product gas products, and then returns the remaining fluid and fission products to the pump bowl. A small amount of fuel salt also leaves the system and travels to the drain tank, where it is pumped back to the pump bowl. The amount of salt sent to the drain tank and back to the pump bowl depends on the flow rate of carrier gas for the off-gas system and the level controls of the drain tank pumping system. Additional information on the off-gas and drain tank systems is detailed in Section 3.2.4.

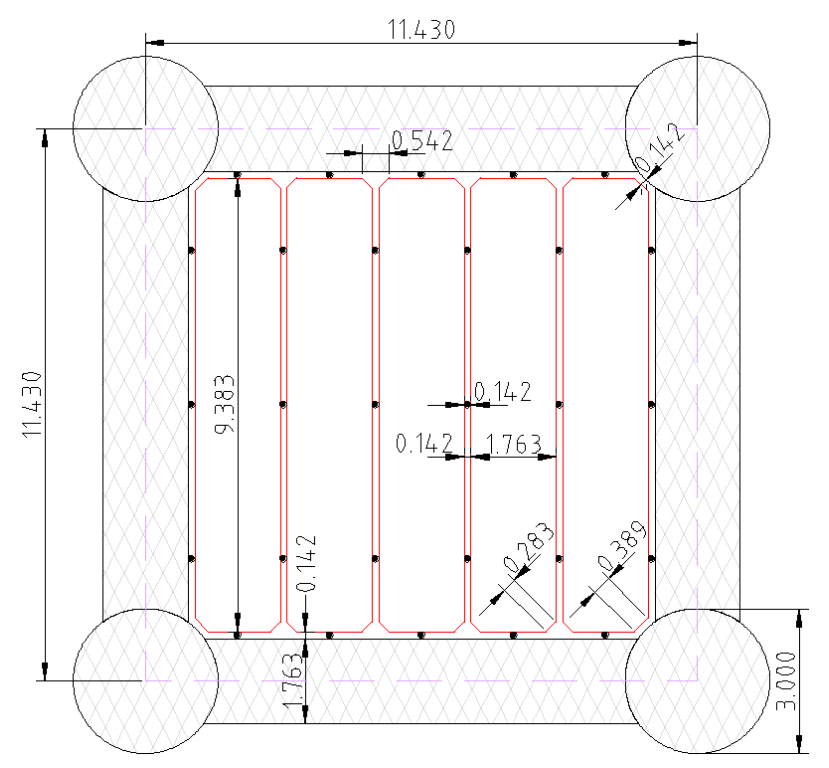

Figure 4. Reproduction of core cell (Bettis, Alexander, and Watts 1972, Fig. 7; ORNL DWG 72-2830). Dimensions in inches; the dashed magenta line indicates a unit cell.

The primary fuel heat exchanger is a simple shelland-tube heat exchanger (Bettis et al., 1972). The primary coolant loop (PCL) is defined as the primary circuit of coolant salt, which includes the primary heat exchanger (coolant side), the coolant pump, the secondary heat exchanger (coolant side), and associated piping.

\subsubsection{Reactor Kinetics \& Fission Product Transport}

The reactor kinetics implementation is a critical component of the system model, as it determines the reactor power output and establishes the behavior of the source terms (generation, reactivity feedback, etc.) throughout the system. The current implementation is based on a modified form of the point reactor kinetics (Greenwood and Betzler, In Review). This model captures the creation, decay, and transport of fission products and the reactivity feedback of neutron absorbers such as xenon, and it includes decay heat in terms of the near- and far-field energy deposition associated with fission product.
Fission product substances such as neutron precursor groups are treated as trace substances transported at the same rate as the primary carrier fluid, as described in the Introduction above. Fission product concentrations and their associated decay are tracked for all fluid volumes throughout the entire system.

\subsubsection{Tritium Transport}

Tritium $\left({ }_{1}^{3} H\right)$ is generated in significant quantities in MSRs. Its source is primarily from interaction of lithium-6 $\left({ }_{3}^{6} L i\right)$ in the carrier salt with neutrons in the reactor vessel. For example, Eqs. (1-4) summarize the major production pathways of tritium in a FLiBe-based system (Stempien, 2015).

$$
\begin{gathered}
{ }_{3}^{6} \mathrm{Li}+{ }_{0}^{1} n \rightarrow{ }_{2}^{4} \mathrm{He}+{ }_{1}^{3} \mathrm{H} \\
{ }_{3}^{7} \mathrm{Li}+{ }_{0}^{1} n \rightarrow{ }_{2}^{4} \mathrm{He}+{ }_{0}^{1} n+{ }_{1}^{3} \mathrm{H} \\
{ }_{4}^{9} \mathrm{Be}+{ }_{0}^{1} n \rightarrow{ }_{2}^{6} \mathrm{He}+{ }_{2}^{4} \mathrm{He} \\
{ }_{2}^{6} \mathrm{He} \rightarrow{ }_{3}^{6} \mathrm{Li}+e^{+}\left(t_{\frac{1}{2}}=0.8 \mathrm{sec}\right)
\end{gathered}
$$

To account for this production, an additional source term for tritium is included in the modified reactor kinetics model based on the composition of the fluid.

Tritium differs from other fission products due to (1) its generation by interaction of salt with neutrons, and (2) the manner in which it readily diffuses through piping at the elevated operating temperatures of MSRs, especially through the thin walls of the heat exchangers (Mays et al., 1977). Using mass transfer analogies to heat transfer, the tritium is permitted to flow from the primary fuel loop to the primary coolant loop and from the primary coolant loop to the balance of plant through the respective heat exchangers. Further details on the methodology can be found in (Rader et al., 2018). Other major components accountable for tritium leaving the primary fuel loop, or tritium management systems, may be incorporated in the future.

\subsubsection{Auxiliary Systems}

An actual MSR, like any industrial scale facility, will have many auxiliary systems. Three systems important to MSRs that are included in the system model are the off-gas system, the drain tank system, and the decay heat removal system. While these systems are important for understanding performance and source term behavior, they are not well defined in literature. Therefore, engineering judgment and simplifications were made for preliminary modeling purposes.

The off-gas system removes a specified set of fission products (i.e., gaseous products) from the primary fuel salt pump bypass line at a specified efficiency using a helium carrier gas (Figure 2). A portion of primary fuel salt is also carried from the primary fuel loop at a rate 
dependent on the carrier gas flow rate. The separated fuel salt travels directly to the drain tank, where it is then pumped back to the pump bowl of the primary fuel loop. The rate of fuel salt return from the drain tank can be controlled using the control settings of the drain tank sump pump. The carrier gas with the separated fission products also travels to the drain tank. The characteristic hold-up time of the gas depends on the tank volume. From the drain tank, the gas is split at a specified ratio between a return line that runs directly back to the pump bowl and a charcoal adsorber bed. As the gas passes through the charcoal bed, substances decay, give off heat, and may become trapped. After exiting the charcoal bed, the carrier gas, along with any remaining substances that did not completely decay or that were otherwise filtered, are returned to the pump bowl.

The charcoal bed transports (Sun et al., 1994) the trace substances between volumes in the adsorber bed at a rate $(m \dot{C})$ which is a function of the inflow rate, the time spent in a volume $(\tau)$, the decay rate of the substance $(\lambda)$, and any sources of each substance from the decay of other substances, as shown in Eq. (5):

$$
m \dot{C}_{\text {out }}=m \dot{C}_{\text {in }} e^{-\lambda \tau}+\sum m \dot{C}_{\text {decay }}
$$

The adsorber bed is heated by the decay of fission products. Like the drain tank heat removal system, the adsorber bed is cooled by a passive circulation loop. For simplicity, a fixed boundary temperature is set for the adsorber bed so that the cooling requirement can be easily monitored, as no design information is available for that system.
The drain tank is separated into two volumes (Figure 2 ), one for the gas and one for the fuel salt. The gas volume is determined by the liquid level of the fuel salt in the specified geometry, while the pressure of the fuel salt volume is set by the gas volume. Products decay and emit heat in each of these volumes and then continue through the process. The gas volume continues to the adsorber bed or goes directly to the pump bowl as previously discussed, while the fuel salt is pumped back to the pump bowl based on the control algorithm implemented. The preliminary control is a level monitor which switches its control setting based on minimum and maximum fuel salt levels. The drain tank is thermally connected with the decay heat removal system through double-walled thimbles, as described below.

The decay heat removal system (Figure 5) is a passive, buoyancy driven, NaK-filled circulation loop. The loop removes heat from the drain tank via double walled thimbles, which rely on radiation heat transfer between the pipes and convective heat transfer between the working fluids and the pipe walls. The hot fluid rejects to a water tank at a higher elevation via identical double-walled thimbles. The cold fluid recirculates back to the drain tank to be reheated. As this system is not well defined, a flow resistance is inserted into the loop so that the mass flow rate matches the design references. This resistance would be comprised of bends, orifices, and other pressure losses not already accounted for by the pressure drop correlations in the pipes. The water tank has a simple control system that maintains the outlet temperature at the design condition. The current model of the water tank includes a simple, ideally mixed volume that does not consider latent heat effects, so the

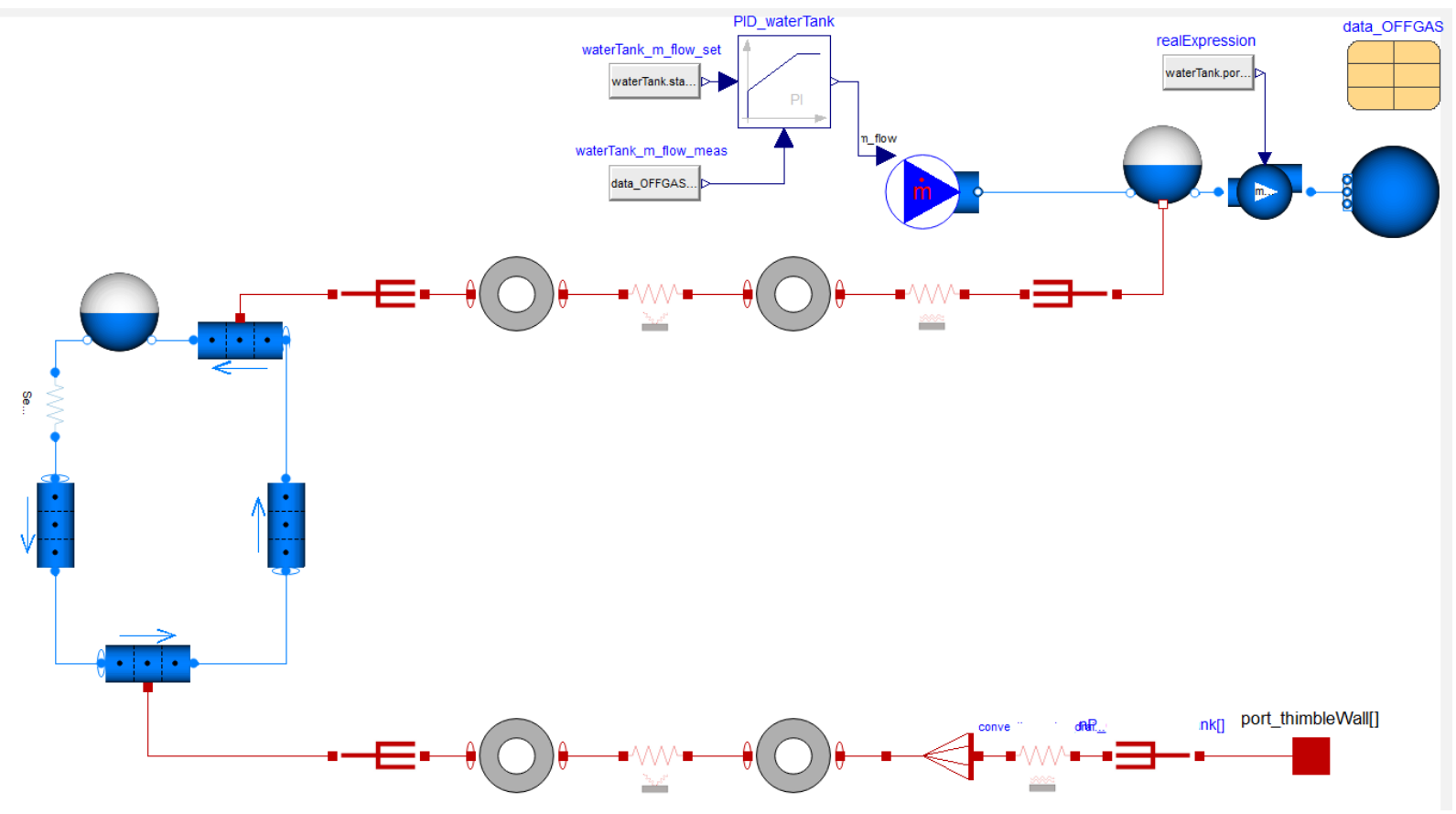

Figure 5. Model of the drain tank natural circulation decay heat removal system. 
flow rate required to keep the tank at design conditions is overestimated.

\section{Results}

There are many various scenarios of potential interest to the regulator body and MSR community. A subset of accident and normal operation scenarios include the following:

- Loss of power

- Single and multiple pump failures

- A variety of reactivity insertion/removal events

- Tritium dose to the environment

- Fission product inventory

- Decay heat removal performance

- Load following ability

- Overall passive safety performance

This list can be quite extensive. Two scenarios are presented herein. The first scenario is a steady-state case with a focus on demonstrating fulfillment or progress on the model criterion. This steady state case also serves as the initial condition for the second case. The second scenario is an accident type scenario in which the primary fuel pump trips, after which the primary coolant pump trips. Under both scenarios, the temperature feedback for the point kinetics equations establishes the power level. At full power, this temperature feedback is assumed to be linear between the nominal inlet and outlet temperature. Exact dimensions/parameters are excluded, and results are normalized, as the cases are meant to demonstrate overall behaviors and capabilities. Simulations were run using Dymola 2018 FD01. Details of the simulation can be found in Table 1 .

Table 1. Simulation Parameters

\begin{tabular}{|l|l|}
\hline Parameter & Value \\
\hline Simulation Time & $172800 \mathrm{~s}$ \\
\hline Real Time & $260 \mathrm{~s}$ \\
\hline Solver & Esdirk45a \\
\hline Tolerance & 0.0001 \\
\hline Equations & 13290 \\
\hline Scalar Equations & 58082 \\
\hline
\end{tabular}

\subsection{Case 1: Steady State Behavior}

A steady-state condition was reached by simulating the model for 172,800 seconds (2 days). The extensive simulation time was due to permitting the reactor to start from zero concentration fission product and therefore required a sufficient length of time for longer lived produces, like xenon (half-life on the order of 9 hours) to build-up to steady-state concentrations.
Figure 6 demonstrates the expected skew of temperature feedback and power based on the assumed linear increase in reference temperature as specified in the case description. The power at the inlet of the core is near zero (though decay heat is still generated) as the fluid enters near the nominal inlet temperature. The power in the subsequent nodes increases due to the temperature feedback, although the profile shifts toward the core outlet due to movement of the precursor neutrons. The temperature difference between the measured and reference temperature decreases toward the outlet of the reactor, decreasing the temperature feedback and slightly lowering the power level of the reactor.

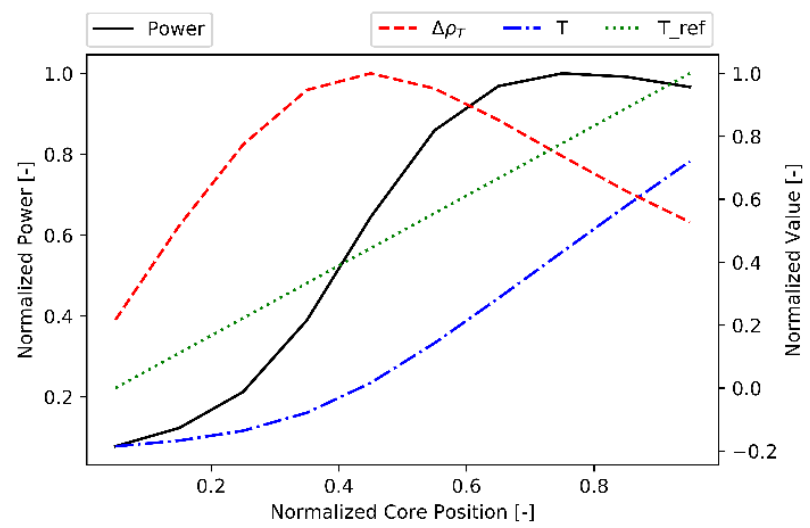

Figure 6. Normalized power and temperature reactivity feedback in the core.

Figure 7 presents the concentration of tritium, a selected neutron precursor group with a relatively short half-life, and xenon as a function of position in the reactor model. The tritium is generated in the core, dependent on the power profile, and then it diffuses through the PFL heat exchanger (HX) to the PCL. Little variation is seen elsewhere due to the long half-life of tritium ( $\sim 12$ years). Neutron precursors, the principle feedback mechanism for point kinetics, are typically separated into several groups. For discussion purposes, only one of the groups, which has a half-life on the order of seconds, is presented. The plot demonstrates the behavior of this group as its generation rate closely follows the power profile of the core and then decays to nearly zero between the core outlet and the PFL HX inlet. Like tritium, xenon's decay rate is slow compared to the loop transit time. However, removal of xenon to the off-gas and charcoal adsorber bed for decay hold-up can be seen in the figure at a position of approximately $10-\mathrm{m}$. The pump bowl is at this position, which has the associated separation process previously described. 


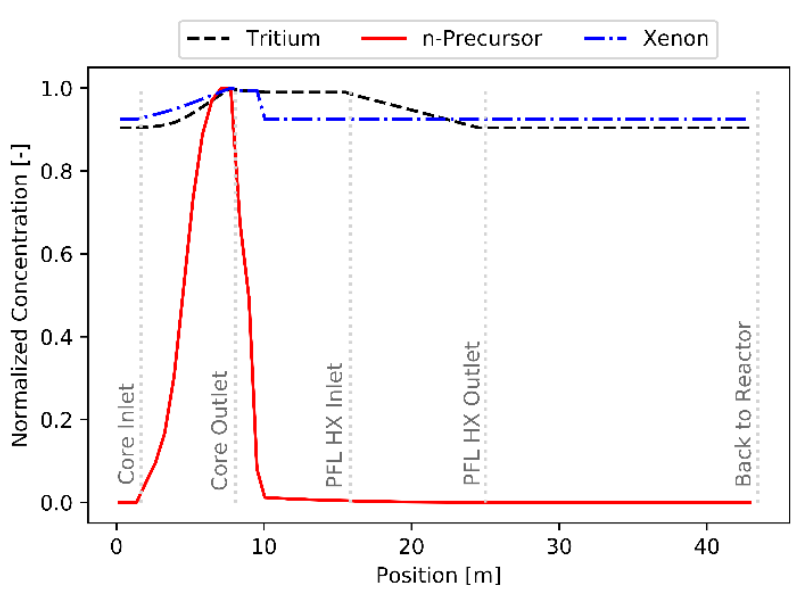

Figure 7. Normalized concentrations of Tritium, a neutron precursor group, and xenon as a function of position in the reactor model.

\subsection{Case 2: Sequential Pump Trips}

Following the two-day simulation, the reactor pumps for the PFL and PCL were ramped down by $95 \%$ from the full power operation flow rate over a period of 60 seconds. The PFL was tripped first, followed by the PCL pump five minutes later. This process can be seen in Figure 8.

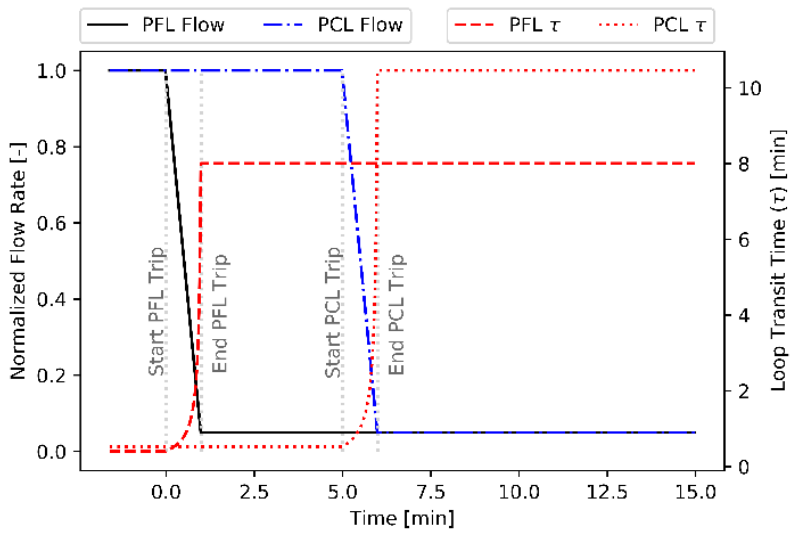

Figure 8. Pump trip event showing the sequential coast down of the PFL and PCL pumps and the associated impact on the respective loop transit times.

Figure 9 - Figure 12 illustrates the feedback on the system due to the drop in PFL flow rate. Upon PFL pump trip, the temperature within the core of the reactor heats up due to the decreased flow rate (Figure 9). As the temperature increases, the temperature feedback of the reactor drives the power down (Figure 10) as it attempts to correct the discrepancy between the reference and measured nodal temperatures. The oscillations in temperature, and therefore reactivity and power, is associated with the influx of colder-thannominal fluid returning from the PFL HX. This fluid is cooled more than usual due to the continued operation of the PCL pump. For clarity Figure 11 and Figure 12 are both presented. These plots illustrate the time- dependent behavior of the entire loop temperature. At the time of the PFL pump trip, the increase in core temperature and decrease in HX temperature are clearly seen. Once the PCL pump trips, the system shifts slightly back toward the nominal condition, as the temperature feedback once again compensates for the off-nominal temperature differences.

Although the change in a variety of behaviors in the PFL is noticeable in the simulation, in the decay heat removal system the heat removal response is very limited, as would be expected since moderate- to longlived isotopes are the primary contributors of decay heat (Figure 10).

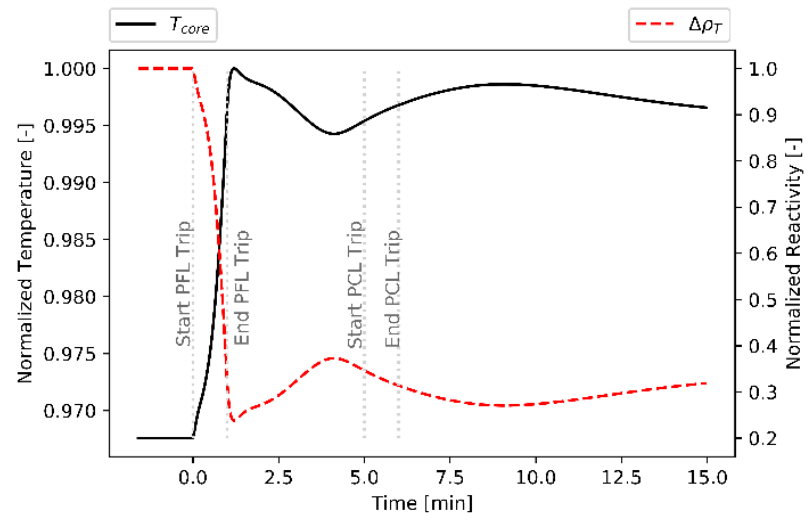

Figure 9. Normalized core temperature and thermal reactivity feedback as a function of time.

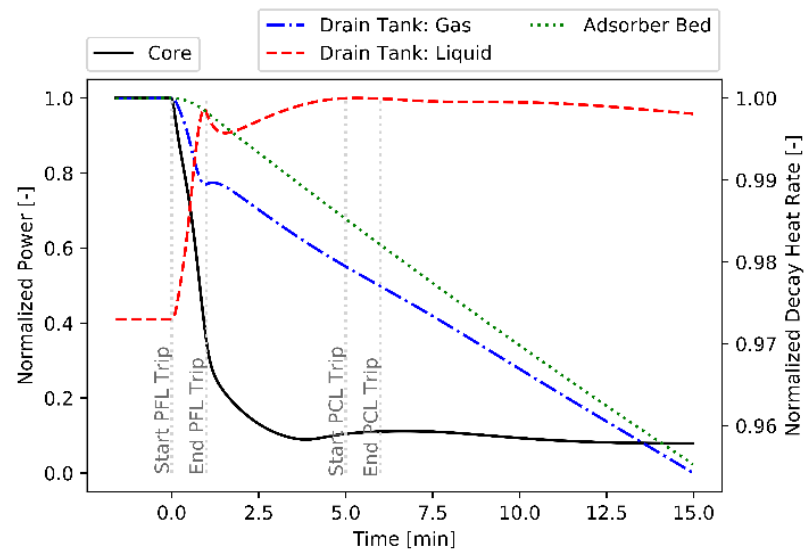

Figure 10. Normalized power generated in the core and removed in the decay heat rejection system. 


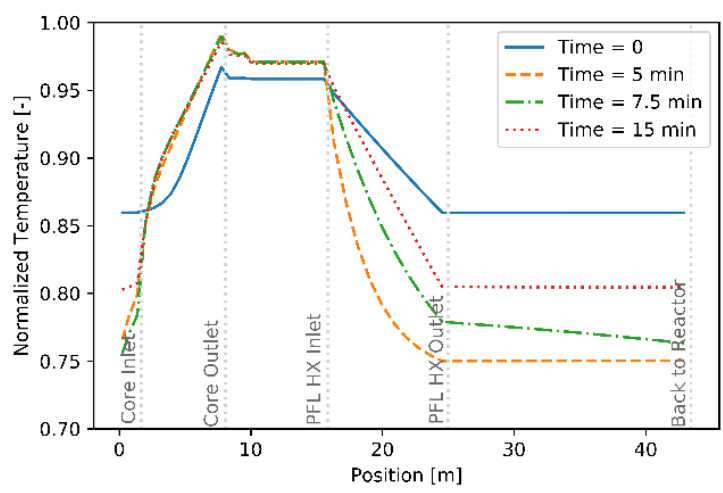

Figure 11. Normalized PFL temperature as a function of loop position for select times throughout the transient case.

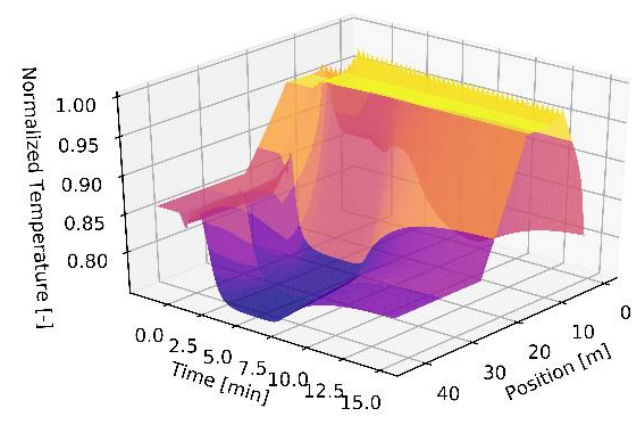

Figure 12. Time history of the evolving PFL temperature as a function of position in the loop.

The tritium release rate oscillates as a function of changes in fluid densities, generation rates, etc. Figure 13 demonstrates the response throughout the system. As expected, the tritium generation rate tracks the power of the reactor. As the initial PFL pump trips the release rate slowly rises, decreases, and rises again. This behavior is due to oscillations in the fluid density (change in tritium volumetric concentration) as temperature waves from the transient case propagate through the system. Once the PCL trips, temperature, and therefore densities and concentrations, return to conditions close to nominal. The difference in release rate of tritium at the beginning and end of simulation are approximately equal due to the amount of tritium being released being a small fraction of the actual amount of tritium in the system. Over longer periods of time, on the order of days, the release rate decreases to match the generation rate.

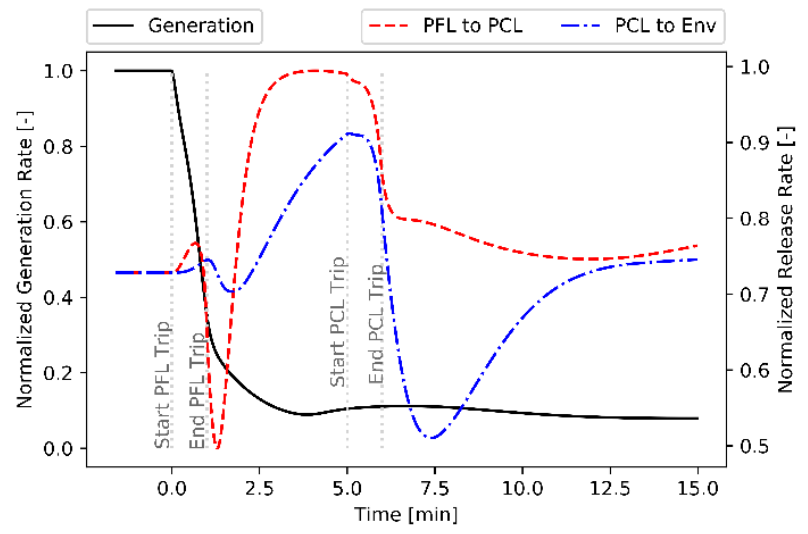

Figure 13. Tritium generation and release rate from the PFL to the PCL and the PCL to the environment (or BOP).

\section{Summary}

To advance the understanding of molten salt-fueled nuclear reactors, a low-fidelity system-level model has been generated in Modelica using the ORNL-developed TRANSFORM library. The simulation relies on the trace substance methodology introduced in the MSL and adopted in TRANSFORM to account for the transport of species, such as fission products, and their impact on the system, including reactivity feedback and decay heat generation. The paper presents a select set of data for steady state and pump-trip scenarios to demonstrate the capabilities and implemented physics of the model. This model will continue to be extended and tailored to specific examples and demonstrations to help identify needs and gaps in data and simulation capabilities in current and future nuclear reactor licensing and design tools. More generally, the presented model and fission product modeling approach demonstrates the ability to advance the understanding of the dynamics of complex fluid-fueled reactor systems, a critical part of licensing and safeguards analysis, for which few if any tools exist.

\section{Acknowledgments}

The author would like to acknowledge and thank the US Department of Energy for funding this work.

\section{References}

Bettis, E. S., Alexander, L. G., and Watts, H. L., 1972. Design Studies of a Molten-Salt Reactor Demonstration Plant (No. ORNL-TM-3832). Retrieved from http://moltensalt.org/references/static/downloads/pdf/ORN L-TM-3832.pdf

Greenwood, M. S., 2017a. TRANSFORM-Library: A Modelica based library for modeling thermal hydraulic energy systems and other multi-physics systems. Modelica, Retrieved from https:/github.com/ORNLModelica/TRANSFORM-Library

Greenwood, M. S., 2017b. TRANSFORM - TRANsient Simulation Framework of Reconfigurable Models. 
Modelica, Oak Ridge National Laboratory. DOI: $10.11578 /$ dc. 20171109.1

Greenwood, M. S., 2017c. Component Development for Nuclear Hybrid Energy Systems (pp. 839-846). Presented at the 12th International Modelica Conference, Prague, Czech Republic. DOI: 10.3384/ecp17132839

Greenwood, M. S., and Betzler, B. R., In Review. Modified Point Kinetic Model for Neutron Precursors and Fission Product Behavior for Fluid-Fueled Molten Salt Reactors. Nuclear Science and Engineering.

Greenwood, M. S., Betzler, B. R., and Qualls, A. L., 2018. Dynamic System Models for Informing Licensing and Safeguards Investigations of Molten Salt Reactors ( No. ORNL/TM-2018/876, 1456790). DOI: 10.2172/1456790

Greenwood, M. S., Cetiner, S. M., Harrison, T. J., and Fugate, D. L., 2017. A Templated Approach for Multi-Physics Modeling of Hybrid Energy Systems in Modelica ( No. ORNL/TM-2018/757). Oak Ridge National Lab. (ORNL), Oak Ridge, TN (United States).

Greenwood, M. S., Fugate, D. W., and Cetiner, S. M., 2017. Control Systems for a Dynamic Multi-Physics Model of a Nuclear Hybrid Energy System. Presented at the 10th International Topical Meeting on Nuclear Plant Instrumentation, Control, and Human-Machine Interface Technologies, San Francisco, CA (United States).

Hale, R. E., Cetiner, S. M., Fugate, D. L., Batteh, J. J., and Tiller, M. M., 2015. Update on Small Modular Reactors Dynamic System Modeling Tool: Web Application ( No. ORNL/SPR--2015/17). Oak Ridge National Laboratory (ORNL), Oak Ridge, TN (United States). DOI: $10.2172 / 1252137$

Hale, R. E., Fugate, D. L., Cetiner, S. M., and Qualls, A. L., 2015. Update on ORNL Transform Tool: Simulating MultiModule Advanced Reactor with End-to-End I\&C ( No. ORNL/SPR-2015/257). Oak Ridge National Laboratory (ORNL), Oak Ridge, TN (United States). DOI: $10.2172 / 1239756$

Hale, R., Fugate, D. L., Cetiner, S. M., Ball, S. J., Qualls, A. L., and Batteh, J. J., 2015. Update on ORNL TRANSFORM Tool: Preliminary Architecture/Modules for HighTemperature Gas-Cooled Reactor Concepts and Update on ALMR Control ( No. ORNL/SPR--2015/367). Oak Ridge National Laboratory (ORNL), Oak Ridge, TN (United States). Retrieved from https://info.ornl.gov/sites/publications/Files/Pub56863.pdf

IAEA, 1972. The Structure and Content of Agreements Between the Agency and States Required in Connection with the Treaty on the Non-Proliferation of Nuclear Weapons ( No. INFCIRC/153 (Corrected)). International Atomic Energy Agency. Retrieved from https://www.iaea.org/publications/documents/infcircs/struc ture-and-content-agreements-between-agency-and-statesrequired-connection-treaty-non-proliferation-nuclearweapons

Mays, G. T., Smith, A. N., and Engel, J. R., 1977. Distribution and Behavior of Tritium in the Coolant-Salt Technology Facility ( No. ORNL/TM-5759). Oak Ridge National Lab. (ORNL), Oak Ridge, TN (United States).

Rabiti, C., Epiney, A. S., Talbot, P., Kim, J. S., Guler Yigitoglu, A., Greenwood, M. S., Cetiner, S. M., et al., 2017. Status Report on Modelling and Simulation
Capabilities for Nuclear-Renewable Hybrid Energy Systems ( No. NL/EXT-17-42441). Idaho National Laboratory.

Rader, J. D., Greenwood, M. S., and Humrickhouse, P. W., 2018. Verification of Modelica-Based Models with Analytical Solutions for Tritium Diffusion. Nuclear Technology, 1-8. DOI: 10.1080/00295450.2018.1431505

Robertson, R. C., 1971. Conceptual Design Study of a SingleFluid Molten-Salt Breeder Reactor ( No. ORNL-4541). Oak Ridge National Laboratory. Retrieved from https://www.osti.gov/scitech/servlets/purl/4030941

Stempien, J. D., 2015, May. Tritium Transport, Corrosion, and Fuel Performance Modeling in the Fluoride SaltCooled High-Temperature Reactor (FHR). Cambridge, MA: Massachusetts Institute of Technology.

Sun, C. L., Chen, J. C., Yu, Y. W., Ha, H. C., Lu, C. S., and Lee, T. Y., 1994. Dynamic adsorption properties of $\mathrm{Kr}$ and Xe isotopes in charcoal. Journal of Radioanalytical and Nuclear Chemistry, 181(2), 291-299. DOI: 10.1007/BF02037635

Touran, N. W., Gilleland, J., Malmgren, G. T., Whitmer, C., and Gates, W. H., 2017. Computational Tools for the Integrated Design of Advanced Nuclear Reactors. Engineering, 3(4), 518-526. DOI: 10.1016/J.ENG.2017.04.016 